\title{
Congenital hypothyroidism in Axenfeld-Rieger syndrome
}

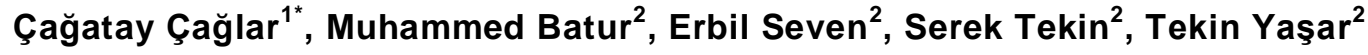 \\ ${ }^{1}$ Ophthalmology Department, Faculty of Medicine, Hitit University, Corum, Turkey \\ ${ }^{2}$ Department of Ophthalmology, Faculty of Medicine, Van Yuzuncu Yil University, Van, Turkey
}

\begin{abstract}
Axenfeld-Rieger syndrome (ARS) manifests varying degrees of anterior segment dysgenesis and carries a risk of resistant glaucoma. It can affect ocular and extraocular structures derived from the neural crest. A small part of the thyroid gland originates from the neural crest, and defects in thyroid origination can result in thyroid agenesis. Thyroid agenesis is a cause of congenital hypothyroidism. We have presented clinical features the first case of ARS associated with congenital hypothyroidism.
\end{abstract}

Key Words: Axenfeld-Rieger syndrome, anterior segment dysgenesis, congenital hypothyroidism, neural crest, thyroid agenesis

\section{Introduction}

Axenfeld-Rieger syndrome (ARS) is mainly characterised by anterior segment abnormalities of the eye, and comprises a clinically and genetically heterogeneous group of conditions with a rare spectrum of developmental disorders involving both ocular and extraocular structures derived from the neural crest. We reported a clinical characteristics the case of ARS with conjenital.

\section{Case report}

A 12-year-old girl presented at a pediatric clinic to obtain a disability report and was referred to ophthalmology clinic for a routine ophthalmologic examination. Her medical history revealed congenital hypothyroidism and growth retardation. She had no personal or family history of ocular abnormalities. An ophthalmological examination showed that her best corrected visual acuity was 1.0 , bilaterally. Her intraocular pressure (IOP) was measured as $13 \mathrm{mmHg}$ by Goldmann applanation tonometer, bilaterally, and the fundus examination was normal, bilaterally. A slit-lamp biomicroscopy and gonioscopy revealed posterior embryotoxon, with strands of peripheral iris tissue extending to the cornea anterior to the Schwalbe's line across $360^{\circ}$, bilaterally (Figures $1 \mathrm{a}, 1 \mathrm{~b}$ and $1 \mathrm{c}$ ). There was a focal iris atrophy in the inferior section of her right eye (Figure 1c). The patient had obvious maxillary hypoplasia, a broad nasal bridge, hypertelorism, microdontia and hypodontia (Figures $2 \mathrm{a}$ and $2 \mathrm{~b}$ ). She also had a significantly short stature and an intermediate level of mental retardation.

The patient has been followed up due to congenital hypothyroidism diagnosis. On her first visit to the pediatric endocrinology clinic, her TSH was $>75.0 \mathrm{uIU} / \mathrm{mL}(0.400-4.00 \mathrm{uIU} / \mathrm{mL})$, her free T4 was $0.441 \mathrm{ng} / \mathrm{dL}(0.80-1.90 \mathrm{ng} / \mathrm{dL})$, and her total T4 was $<1.00 \mathrm{ng} / \mathrm{dL}(4.50-12.5$ $\mathrm{ng} / \mathrm{dL}$ ). The thyroid was non-palpable on physical examination. There was no thyroid gland identified in the thyroid ultrasonography. There was no uptake activity at the location of the thyroid gland in the thyroid scintigraphy (Figure 3). According to this data, the diagnosis was congenital hypothyroidism caused by the congenital agenesis. The patient's karyotype analysis was performed and the result was normal. The patient takes L-thyroxine $(100 \mu \mathrm{g} / \mathrm{day})$ and her congenital hypothyroidism is being followed up by the pediatric endocrinology clinic.

The patient has been followed up for 8 years. In the second year of the patient's follow-up,

This report was presented as a poster presentation "43. National Congress of Turkish Ophthalmology Association, $11-15$ November 2009, Beldibi, Antalya, Turkey".

*Corresponding Author: Erbil Seven MD. Department of Ophthalmology, Faculty of Medicine, Yuzuncu Yil University, 65080, Tusba, Van, Turkey, Phone Number: +90 (505) 29256 28, Fax Number: +90 (432) 21683 52, E-mail address: erbilseven@gmail.com 
glaucoma was diagnosed in the left eye. Latanoprost $0.005 \%$ eye drop was prescribed one drop per day for left eye. The patient's glaucoma is still under control with latanoprost eye drop.

\section{Discussion}

Axenfeld-Rieger syndrome is mainly characterized by anterior segment abnormalities of the eye, and comprises a clinically and genetically heterogeneous group of conditions with a rare spectrum of developmental disorders involving ocular and extraocular structures derived from the neural crest. It is associated with secondary glaucoma in about $50 \%$ of cases, because of peripheral anterior synechiae and secondary angle closure of the anterior chamber angle (1). In our case, the IOP and cup-disc ratio was normal.

Ocular manifestations of ARS involve iris stromal hypoplasia, ectropion uveae, corectopia, fullthickness iris defects, severe iris atrophy and peripheral anterior synechiae (2). A typical abnormality of the cornea is a prominent anteriorly displaced Schwalbe's line (posterior embryotoxon), which appears as a white ring on the posterior cornea, near the limbus. This tends to be more common temporally and rarely involves the full $360^{\circ}$. In our case, a $360^{\circ}$ Schwalbe's ring existed in slit-lamp biomicroscopy in each eye. Non-ocular manifestations of ARS
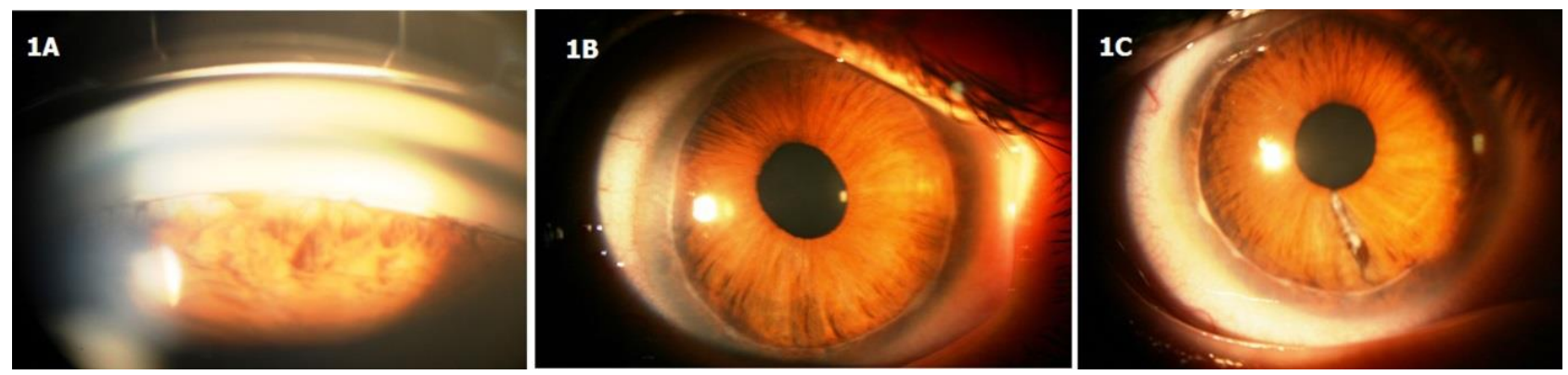

Fig. 1a. Gonioscopy revealed posterior embryotoxon. (b) Peripheral iris tissue, which appears as a white ring on the posterior cornea anterior to Schwalbe's line across $360^{\circ}$ in the left eye. (c) Focal iris atrophy in the inferior section of the right eye.

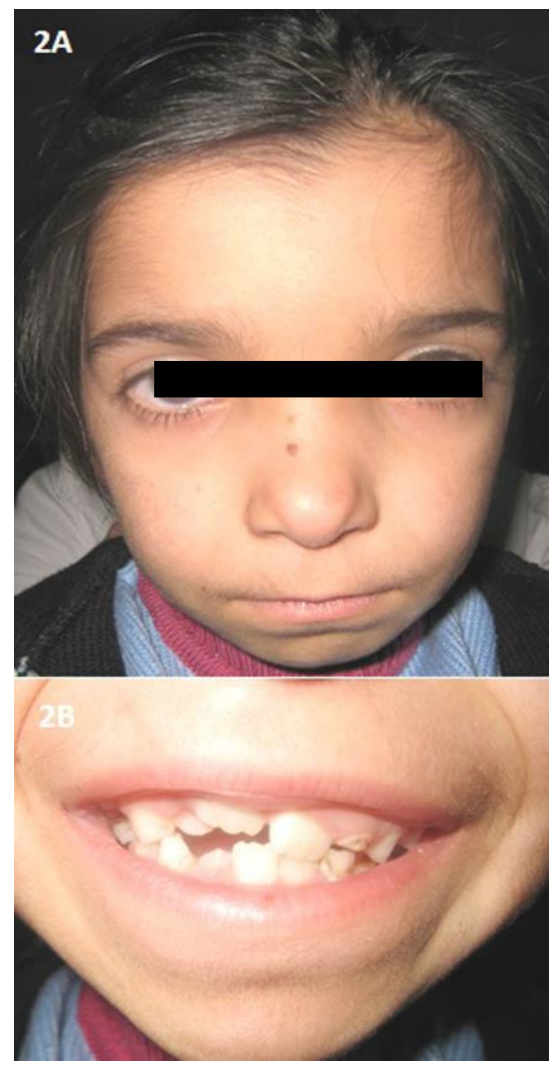

Fig. 2a. Obvious maxillary hypoplasia, broad nasal bridge, hypertelorism. (b) Microdontia and hypodontia.

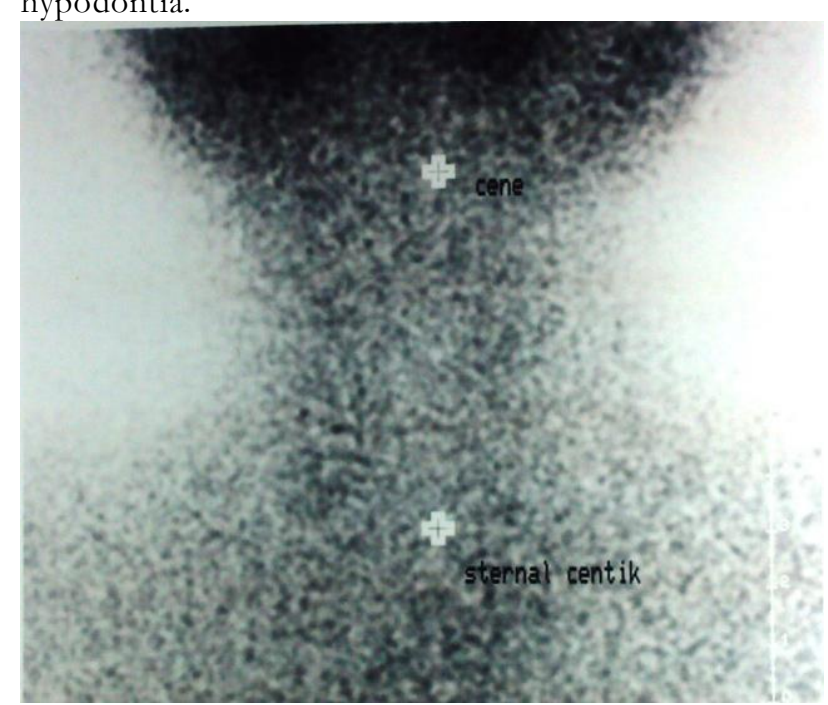

Fig. 3. No activity

thyroid gland in thyroic

may include developmental defects of the teeth and facial bones, pituitary anomalies, cardiac disease, oculocutaneous albinism, and redundant periumbilical skin (2-3). Failed neural crest cell migration and differentiation during embryonic 
development are considered important in the pathogenesis of ARS (3). This is because neural crest cells form large portions of the ocular anterior segment, including the iris stroma, cornea, and structures of the iridocorneal angle, such as Schwalbe's line (4-5). The common origin of Schwalbe's line and iris stroma from the neural crest cells could explain the presence of the detached Schwalbe's line, with attached iris tissue strands in the anterior chamber. Neural crest cells also compose, or contribute to the formation of, many systemic structures. Malformations of the sella turcica and pituitary gland, face, umbilical tissues, teeth and skeletal system associated with ARS can be attributed to their origin in the neural crest (5). The main part of the thyroid gland originates from the primitive pharynx endoderm, and the gland's lateral section originates from the ventral part of the fourth and fifth pharyngeal pouches. The neural crest cells (ultimobranchial bodies) of these two pouches assist the development of parafollicular cells (C cells) (6). Defects in the thyroid specification can result in thyroid agenesis (or thyroid dysgenesis); i.e., a total absence of the gland as a consequence of impaired organogenesis. Thyroid agenesis is a cause of congenital hypothyroidism. Approximately $80 \%$ of cases of congenital hypothyroidism are caused by thyroid dysgenesis due to the absence, hypoplasia or ectopia of the gland, in our case, the thyroid agenesis may be resulted from the defect of the neural crest cell migration and differentiation. In the case of our patient, the diagnosis of primary congenital hypothyroidism was confirmed by demonstrating decreased levels of serum thyroid hormone (total or free T4) and elevated levels of thyroidstimulating hormone. Isotope scanning has recently become the gold standard when scanning children with congenital hypothyroidism, and it is the primary method of revealing an ectopic gland, although it is less helpful in the evaluation of thyroid dimensions and morphology (7). However, ultrasound scanning can detect non-functioning thyroid tissue that cannot be identified through isotope scanning, as well as showing abnormalities in volume and morphology (8). The scintigraphy and thyroid ultrasonography provided informative data to help determine the etiology of our case; the cause of congenital hypothyroidism was found to be thyroid agenesis. In turn, congenital hypothyroidism had caused mental retardation.
Congenital hypothyroidism based on congenital agenesis has not previously been reported in association with ARS. However, in these cases, mental and growth retardation secondary to hypothyroidism can improve. Therefore, patients with ARS should be investigated for hypothyroidism, as an early diagnosis and treatment of congenital hypothyroidism is crucial to ensuring mental, physical and neurological development.

Financial interest: The author(s) have no financial interest in any materials discussed in this article. No funding or grant support were received for this study.

Conflict of interest: None of the authors have any proprietary interests or conflicts of interest related to this submission. This manuscript has not been sent another journal.

\section{References}

1. Shields MB. Axenfeld -Rieger syndrome: a theory of mechanism and distinctions from the iridocorneal endothelial syndrome. Trans Am Ophthalmol Soc 1983 ;81: 736-84.

2. Dhir L, Frimpong-Ansah K, Habib NE. Missed case of Axenfeld-Rieger syndrome: a case report. Cases J 2008; 1: 299.

3. Shields MB, Buckley E, Klintworth GK, Thresher R. Axenfeld-Rieger syndrome. A spectrum of developmental disorders. Surv Ophthalmol 1985; 29: 387-409.

4. Idrees F, Vaideanu D, Fraser SG, Sowden JC, Khaw PT. A review of anterior segment dysgeneses. Surv Ophthalmol 2006; 51: 213-231.

5. Tripathi BJ, Tripathi RC. Neural crest origin of human trabecular meshwork and its implications for the pathogenesis of glaucoma. Am J Ophthalmol 1989; 107: 583-590.

6. Policeni BA, Smoker WR, Reede DL. Anatomy and embryology of the thyroid and parathyroid glands. Semin Ultrasound CT MR 2012; 33(2): 104-114.

7. Perry RJ, Maroo S, Maclennan AC, Jones JH, Donaldson MD. Combined ultrasound and isotope scanning is more informative in the diagnosis of congenital hypothyroidism than single scanning. Arch Dis Child 2006; 91: 972-976.

8. Kreisner E, Camargo-Neto E, Maia CR, Gross JL. Accuracy of ultrasonography to establish the diagnosis and aetiology of permanent primary congenital hypothyroidism. Clin Endocrinol 2003; 59: 361-365. 